\title{
林业资源型城市生态-经济-社会协调发展的定量测度
} 以黑龙江省伊春市为例

\author{
姜晓艳, 吴相利 * \\ 哈尔滨师范大学地理科学学院, 哈尔滨 150025
}

摘要:把握城市独特的生态-经济-社会系统协调优化特性是实现林业资源型城市可持续发展的重要前提。研究从生态、经济、 社会 3 个维度构建了林业资源型城市复合系统的测度评价指标体系,应用熵值法、耦合协调度模型,采用 2005 -2018 年时段生 态、经济、社会数据,对伊春协调发展状况进行实证测度评价,运用障碍度模型分析影响系统协调发展的主要因素, 采用 GM(1, 1) 灰色预测模型进行发展预测。结果表明:(1) 综合发展指数呈上升态势,促进生态-经济-社会综合发展的主要动能历经了从 生态到经济,再到生态为主要动力的发展过程,三个子系统发展水平呈趋同态势, 推动三维系统的均衡协同是未来发展的重要 方向; (2)三维系统耦合度稳定在较高水平, 系统间相互依赖、相互作用程度较高,协调度呈波动上升,实现了由勉强协调、经济 滞后发展向良好协调、同步发展的转变,协调状态趋向良好; (3) 三维系统中社会子系统对协调发展的障碍度最大; 人口自然增 长率、建成区绿化覆盖率、GDP 增长率、第三产业就业人数比重 4 个指标是制约近期协调发展的主要障碍因子; (4)2019一2030 年,生态、经济、社会子系统发展指数及协调度的预测值均呈上升态势,生态-经济-社会复合系统将向更高级的协调发展状态演 进, 经济发展将再次成为促进生态-经济-社会综合发展的主要动力; 加强生态建设,引领生态创新, 大力发展生态经济,提高社 会发展水平,着力降低障碍因子对协调发展的阻力作用,实现生态-经济-社会的联动健康发展是伊春未来重要的努力方向。

关键词: 林业资源型城市;生态-经济-社会;耦合协调;障碍度;伊春市

\section{Quantitative investigation of the coordinated development of ecology-economy- society in forest resource-based city: A case study of Yichun, Heilongjiang Province}

JIANG Xiaoyan, WU Xiangli*

College of Geographical Science, Harbin Normal University, Harbin 150025, China

\begin{abstract}
Understanding the city's unique ecological-economic-social system coordination and optimization characteristics is an important prerequisite for achieving sustainable development of forestry resource-based cities. This study constructed a measurement and evaluation index system of the forestry resource-based city composite system from three dimensions of ecology, economy and society. Entropy method and coupling coordination degree model were used to evaluate the coordinated development of Yichun City by using the ecological, economic, and social data from 2005 to 2018 . The obstacle degree model was used to analyze the main factors that affected the coordinated development and the GM (1,1) gray forecast model was used for development prediction. The results show that: (1) the comprehensive development index is on the rise. The main driving force to promote the comprehensive development of ecology, economy and society has gone through the development process from ecology to economy, and then ecology as the main driving force. On the whole, the
\end{abstract}

基金项目: 国家自然科学基金项目 (41171433); 国家社会科学基金项目(16BJY039);黑龙江省自然科学基金项目(D2018003)

收稿日期: 2020-09-07; 网络出版日期:2021-07-05

*通讯作者 Corresponding author.E-mail: jndxwxl@163.com 
development momentum is increasingly converging. Promoting the balanced coordination of the three-dimensional system is an important direction for future development. (2) The coupling degree of the three-dimensional system is stable at a relatively high level. The interdependence and interaction between the subsystems are relatively high and the degree of coordination fluctuates, which realizes the transformation from barely coordinated and backward economic development to good coordinated and synchronous development. The state of coordination tends to be good; (3) The social subsystem in the three-dimensional system has the greatest obstacle to the coordinated development. Four indicators, including the natural population growth rate, the green coverage rate of the built-up area, the GDP growth rate, and the proportion of employment in the tertiary industry, are the main obstacle factors restricting the near-term coordinated development; (4) From 2019 to 2030, the development index of ecological, economic, and social subsystem and the predicted value of coordination are all on the rise, which means the ecological-economic-social comprehensive system would evolve to a better state of coordination development, among which the economic subsystem will once again be the main driving force to push the ecologicaleconomic-social comprehensive development of the city. It is suggested that Yichun should put its emphasis on strengthening the ecological construction, guiding ecological innovation, striving to developing ecological economy, improving the level of social development, making efforts to reduce the resistance of obstacle factors to coordinated development, and realizing the linkage and healthy development of the three, which is an important direction for the future development of Yichun.

Key Words: forestry resource-based city; ecology-economy-society; coupling and coordination; obstacle degree; Yichun City

伊春位于小兴安岭腹地,是我国最大的国有林区和国家木材后备基地。50 余年的持续开发导致伊春“因 林而生、因林而兴、因林而衰”,2000 年前后已面临资源、经济的两危困境 ${ }^{[1]}$,人口收缩、老龄化严重、社会保障 水平低等问题日趋加重并呈群发现象,生态、经济、社会系统间相互掣肘矛盾日益突显。在可持续发展战略的 背景下,伊春市被相继确定为我国首批资源枯竭型城市 (林业)、衰退型林业资源型城市、资源型经济转型试 点城市、“天保工程”试点城市、国家重点建设的生态主体功能区等, 享受相关政策红利。但从实际发展水平 上看, 近十年社会经济发展虽有所起色, 总体却仍在低谷俳徊。从生态主体功能区建设、经济转型发展、社会 健康的发展目标上看, 全面研究其生态-经济-社会系统耦合协调发展状态过程, 破除制约协调发展因素, 探究 优化系统发展对策路径具有重要的现实意义。伊春是我国典型的林业资源型城市,其研究范式与发展经验对 我国众多林业城市发展研究都具有良好的借鉴意义。

国外关于生态、经济、社会协调发展的研究较为成熟,学者们较早地注意到经济发展过程中的环境质量问 题 ${ }^{[2]}$ 。Cumberland 运用投人产出模型研究经济生产活动与生态环境的相关系数 ${ }^{[3]}$ 。Grossman 等运用环境库 兹涅茨曲线 $\left(\mathrm{EKC}\right.$ ) 研究环境质量与人均收人间的关系 ${ }^{[4]}$, 学者们进行了关于环境库兹涅茨曲线假说的综述 和实证研究,并指出了环境与经济发展关系的多样性 ${ }^{[5-6]}$, 推进了以 “可持续发展” 为核心的生态、经济、社会 协调发展主题 ${ }^{[7-8]}$, 基于数据包络分析法 (DEA $)^{[9]}$ 、生态足迹法 ${ }^{[10]}$ 等方法模型的定量研究。相比之下, 国内 研究起步较晚, 但成果也较为丰富。其中, 一部分学者侧重于探讨生态环境与经济发展的协调关系并将其拓 展到三维系统, 研究内容主要集中在城市化与生态环境 ${ }^{[11-13]}$ 、环境与经济 ${ }^{[14]}$ 、旅游-生态-经济环境 ${ }^{[15-16]}$ 的耦 合协调发展关系等方面。另一部分学者侧重于生态-经济-社会的耦合协调关系,并将其扩展到四维系统。马 世骏提出社会-经济-自然复合生态系统 ${ }^{[17]}$, 毛汉英早在 1991 年便探讨了县域 PRED 协调发展的目标、指导思 想和研究方法 ${ }^{[18]}$ 。学者们从生态文明建设 ${ }^{[19]}$ 等角度, 国家 ${ }^{[19]}$ 、省域 ${ }^{[20]} 、$ 地区 ${ }^{[21]}$ 、典型城市 ${ }^{[22]}$ 、县域 ${ }^{[23]} 、$ 城市 群 ${ }^{[24]}$ 等多个尺度进行分析和实证研究。同时,资源型城市 ${ }^{[25]}$ 的发展问题也备受关注,学者们在林业资源型 城市的城市转型 ${ }^{[26]}$ 、经济转型 ${ }^{[27]}$ 、可持续发展 ${ }^{[28]}$ 研究方面取得一定进展。Markey 等在对加拿大不列颠哥伦

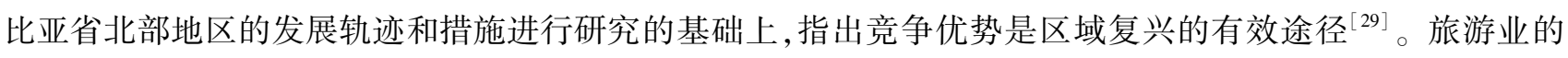
增长和耕作方式的改变促进了新西兰南岛海岸两个停止采伐旧林的资源依赖型小型社区减轻林业损失和社 
区衰退的能力 ${ }^{[30]}$ 。

已有研究为林业资源型城市生态-经济-社会的耦合协调发展研究提供了一定的理论和实践基础,但少有 学者研究林业资源型城市生态-经济-社会耦合协调关系,且偏向于将经济系统和社会系统合成社会经济系 统 ${ }^{[31}$ 进行评价, 缺乏对三维系统发展水平的分析及耦合协调发展的预测。本文以林业资源型城市伊春为例 构建生态-经济-社会复合系统, 运用熵值法及耦合协调度模型测度 2005-2018 年间各子系统发展水平及三 者耦合协调度,应用障碍度模型诊断阻碍伊春协调发展的障碍因子, 并借助 $\operatorname{GM}(1,1)$ 灰色预测模型对伊春生 态-经济-社会未来的协调发展情况进行预测 , 以期为林业资源型城市生态-经济-社会协调发展提供一定的科 学依据。

\section{1 研究区概况与指标数据}

\section{1 研究区概况}

本研究区范围为伊春市辖行政区域范围 (图 1), 面积 3.3 万 $\mathrm{km}^{2}$ 。其中, 自然保护区总面积达 672462 $\mathrm{hm}^{2}$, 占行政区划面积的 $20.52 \%$, 森林覆盖率达 $84.7 \%$, 远高于全国平均水平。2018 年全市实现生产总值 274.15 亿元, 较上年增长 $6 \%$, 低于全国平均水平 $0.1 \%$ 。城镇恩格尔系数 $31.8 \%$, 养老保险参保人数 307711 人, 城镇登记失业率为 $3.94 \%$ 。近年来, 伊春人口呈负增长态势, 人口持续外流, 2018 年年末总人口为 114.1 万人, 较 2005 年减少 14.7 万。

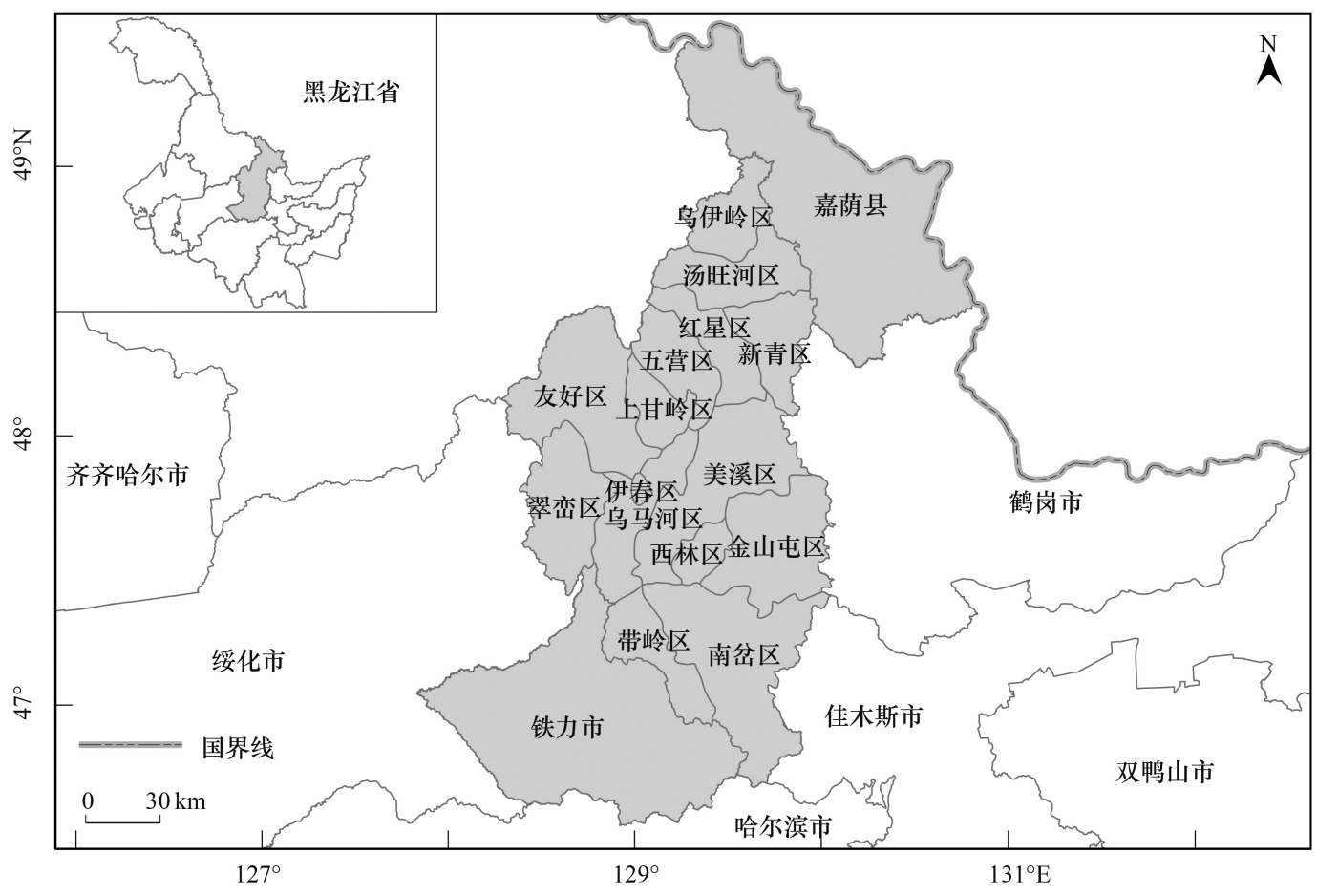

图 1 研究区

Fig.1 Study area

1.2 指标体系构建与数据来源

从协调发展理念出发, 借鉴已有研究成果 ${ }^{[15,19]}$, 结合大小兴安岭地区生态功能区建设指标、国家“生态 市” 建设指标 ${ }^{[32]}$, 针对林业资源型城市现状, 围绕生态、经济、社会 3 个维度, 构建了能反映伊春生态-经济-社 会发展水平的综合评价体系 (表 1)。其中,生态子系统基于 “压力-状态-响应” 模型, 从生态基础、生态压力、 生态响应 3 个视角选取指标, 目的是反映经济生产、社会生活及生态环境的互动效应; 经济子系统以“可持续 
发展” 为原则, 从经济基础、经济结构、经济质效 3 个方面选取指标, 目的是系统地反映城市经济发展质量; 社 会子系统重点选取人口就业、居民生活水平、社会保障等反映民生发展的指标。初选指标后利用因子分子和 主成分分析验证指标的合理性,最终确定 31 个指标因子。指标层及准则层的权重由熵值法 ${ }^{[24,33]}$ 确定, 并通 过加权求和获得各子系统的发展指数。指标数据来源于 2006-2019 年《伊春统计年鉴》、《黑龙江统计年 鉴》、部分数据来源于 2005-2018 年《伊春市国民经济和社会发展统计公报》,少数缺失数据通过插值法补 齐,并在数据使用前对原始数据进行极差标准化和无量纲处理。

表 1 生态-经济-社会系统协调发展评价体系

Table 1 Evaluation System for coordinated development of Ecological, Economy and Society

\begin{tabular}{|c|c|c|c|c|c|}
\hline $\begin{array}{l}\text { 系统层 } \\
\text { System laver }\end{array}$ & 准则层 & 权重 & 指标层 & 指示方向 & 权重 \\
\hline 生态子系统 $A$ & $A_{1}$ 生态基础 & 0.259 & $A_{11}$ 森林覆盖率/\% & + & 0.053 \\
\hline \multirow[t]{9}{*}{ Ecological subsystem $A$} & & & $A_{12}$ 年降水量/mm & + & 0.074 \\
\hline & & & $A_{13}$ 人均公园绿地面积 $/ \mathrm{m}^{2}$ & + & 0.132 \\
\hline & $A_{2}$ 生态压力 & 0.500 & $A_{21}$ 万元 GDP 工业废水排放量/t & - & 0.078 \\
\hline & & & $A_{22}$ 单位 GDP 能耗/( 吨标准煤/万元) & - & 0.114 \\
\hline & & & $A_{23}$ 万元 GDP 烟粉尘排放量/t & - & 0.095 \\
\hline & & & $A_{24}$ 农用化肥施用量( 折算量) / t & - & 0.213 \\
\hline & $A_{3}$ 生态响应 & 0.241 & $A_{31}$ 建成区绿化覆盖率/\% & + & 0.090 \\
\hline & & & $A_{32}$ 污水集中处理率/\% & + & 0.043 \\
\hline & & & $A_{33}$ 空气质量达标率/\% & + & 0.108 \\
\hline 经济子系统 $B$ & $B_{1}$ 经济基础 & 0.297 & $B_{11}$ 地区生产总值/万元 & + & 0.082 \\
\hline \multirow[t]{9}{*}{ Economic subsystem $B$} & & & $B_{12}$ 财政收人/万元 & + & 0.104 \\
\hline & & & $B_{13}$ 固定资产投资总额/万元 & + & 0.111 \\
\hline & $B_{2}$ 经济结构 & 0.352 & $B_{21}$ 第三产业产值比重/\% & + & 0.138 \\
\hline & & & $B_{22}$ 固定资产投资相当于 GDP 比例 $/ \%$ & + & 0.121 \\
\hline & & & $B_{23}$ 进出口总额相当于 GDP 比例 $/ \%$ & + & 0.093 \\
\hline & $B_{3}$ 经济质效 & 0.351 & $B_{31}$ 人均生产总值/元 & + & 0.077 \\
\hline & & & $B_{32}$ 职工平均货币工资/元 & + & 0.108 \\
\hline & & & $B_{33}$ GDP 增长率/\% & + & 0.042 \\
\hline & & & $B_{34}$ 人均消费品零售额/元 & + & 0.123 \\
\hline 社会子系统 $C$ & $C_{1}$ 人口就业 & 0.323 & $C_{11}$ 总人口/万人 & + & 0.056 \\
\hline \multirow[t]{10}{*}{ Social subsystem $C$} & & & $C_{12}$ 自然增长率/\%o & + & 0.045 \\
\hline & & & $C_{13}$ 城市人口密度/ $\left(\right.$ 人 $\left./ \mathrm{km}^{2}\right)$ & + & 0.119 \\
\hline & & & $C_{14}$ 第三产业就业人数比重 $/ \%$ & + & 0.103 \\
\hline & $C_{2}$ 生活水平 & 0.327 & $C_{21}$ 城镇居民可支配收人/元 & + & 0.145 \\
\hline & & & $C_{22}$ 农民人均纯收人/元 & + & 0.110 \\
\hline & & & $C_{23}$ 恩格尔系数 $/ \%$ & + & 0.072 \\
\hline & $C_{3}$ 社会保障 & 0.351 & $C_{31}$ 每万人拥有卫生技术人员/人 & + & 0.108 \\
\hline & & & $C_{32}$ 教育事业费支出相当于 GDP 比例 $/ \%$ & + & 0.064 \\
\hline & & & $C_{33}$ 养老保险参保人数/万人 & + & 0.138 \\
\hline & & & $C_{34}$ 社会保障和就业支出比重/\% & + & 0.041 \\
\hline
\end{tabular}

\section{2 研究方法}

2.1 熵值法

熵值法是一种客观赋权法,可以客观真实地反映隐含在指标数据中的信息。因此,可以利用其计算出评 价指标权重, 为综合评价提供依据。计算过程如下: 
(1) 数据极差标准化处理, 对于含正负向的指标数据进行极差标准化处理, 公式如下:

正向指标:

$$
\begin{aligned}
& X^{\prime}{ }_{i j}=\left(X_{i j}-X_{j \min }\right) /\left(X_{j \max }-X_{j \min }\right) \\
& X^{\prime}{ }_{i j}=\left(X_{j \max }-X_{i j}\right) /\left(X_{j \max }-X_{j \min }\right)
\end{aligned}
$$

$X_{i j}$ 为第 $i$ 年第 $j$ 项指标的值, $X_{\text {jmax }} 、 X_{j \min }$ 为第 $j$ 项指标的最大值、最小值。

(2) 熵值法 ${ }^{[24,33]}$ 计算出各指标的权重及各子系统的综合评价值 (发展指数), 过程如下:

首先,计算第 $i$ 年第 $j$ 项指标值的比重:

$$
Y_{i j}=X_{i j}^{\prime} / \sum_{i=1}^{m} X_{i j}^{\prime}
$$

然后,计算第 $j$ 项指标的信息熵:

$$
e_{j}=-1 / \ln m \sum_{i=1}^{m}\left(Y_{i j} \times \ln Y_{i j}\right) \quad\left(0 \leqslant e_{j} \leqslant 1\right)
$$

其次,计算第 $j$ 项指标的权重:

最后,计算各子系统第 $i$ 年的发展指数:

$$
w_{j}=\left(1-e_{j}\right) / \sum_{j=1}^{n}\left(1-e_{j}\right)
$$

$$
f(x) \operatorname{org}(y) \operatorname{orh}(z)=\sum_{j=1}^{n} w_{j} \times X^{\prime}{ }_{i j}
$$

式中, $Y_{i j}$ 为第 $i$ 年第 $j$ 项指标的比重, $X^{\prime}{ }_{i j}$ 为极差标准化后的指标值, $m$ 为年数, $e_{j}$ 为熵值, $n$ 为指标数, $f(x)$ 、 $g(y) 、 h(z)$ 分别为生态、经济、社会子系统的综合评价值,即发展指数。

\section{2 耦合协调度模型}

耦合协调度描述两个或两个以上系统相互作用影响的程度,耦合作用和协调程度决定了系统发展状 况 $^{[34]}$; 本文借鉴容量耦合系数模型构建林业资源型城市生态-经济-社会的耦合协调度模型。公式如下:

$$
\begin{gathered}
C=\left\{\left[\frac{f(x) \times g(y) \times h(z)}{\left[\frac{(f(x)+g(y)+h(z))}{3}\right]^{3}}\right\}^{1 / 3}\right. \\
T=\alpha f(x)+\beta g(y)+\delta h(z), D=\sqrt{C \times T}
\end{gathered}
$$

式中, $C$ 为耦合度, $f(x) 、 g(y) 、 h(z)$ 分别为生态、经济、社会子系统的综合评价值,也称发展指数, 由各准则 层的评价值累加得到; $T$ 为 3 个子系统的综合发展指数, $\alpha 、 \beta 、 \delta$ 为调节系数, 本文认为生态、经济、社会子系 统同等重要, 故令 $\alpha=\beta=\delta=1 / 3 ; D$ 为协调度, 表示三者的协调发展程度, 本文将廖重斌 ${ }^{[35]}$ 协调度的划分大类 与张青峰等 ${ }^{[21]}$ 协调度的子类划分方法相结合并扩展到三维系统作为本文协调度划分标准。

2.3 障碍度模型

运用障碍度模型 ${ }^{[36]}$, 诊断影响伊春生态-经济-社会协调发展的障碍因素, 利于政府采取针对性措施促进 协调发展。计算步骤如下:

$$
M_{j}=\left(1-X_{j}\right) \times\left(W_{i} \times P_{i j}\right) \times 100 \% / \sum_{i=1}^{31}\left(1-X_{j}\right) \times\left(W_{i} \times P_{i j}\right), B_{i}=M_{i j}
$$

式中, $M_{j}$ 为单项指标 $j$ 的障碍度, $B_{i}$ 为系统 $i$ 的障碍度, $X_{i j}$ 为单项指标采用极差标准化方法得到的标准化值, $W_{i}$ 为第 $i$ 个系统的权重, $P_{i j}$ 为第 $i$ 个系统中第 $j$ 个指标权重。

$2.4 \operatorname{GM}(1,1)$ 灰色预测模型

灰色系统理论是研究解决灰色系统分析、建模、预测、决策和控制的理论 ${ }^{[37]}$, 常用数列预测、灾变与异常 值预测、季节灾变与异常值预测、拓扑预测、系统预测 5 种 ${ }^{[15]}$ 。本文采用数列预测对发展指数及协调度进行 预测。具体操作如下:

(1) 设原始数列 $x^{(0)}=\left(x^{(0)}(1), x^{(0)}(2) \cdots x^{(0)}(M)\right)$, 对原始数列作一次累加生成得到新数列 $x^{(1)}=$ 
$\left(x^{(1)}(1), x^{(1)}(2) \cdots x^{(1)}(M)\right)$, 则近似微分方程为:

$$
\mathrm{d} x^{(1)} / \mathrm{d} t+a x^{(1)}=u
$$

(2) 通过最小二乘法拟合得到 $a 、 u$ :

$$
\left[\begin{array}{l}
a \\
u
\end{array}\right]=\left(B^{T} B\right)^{-1} B^{T} Y_{M}
$$

(3) 将所求值代人时间响应函数:

$$
\hat{x}^{(1)}(k+1)=\left[x^{(1)}(1)-\frac{u}{a}\right] e^{-a t}+\frac{u}{a}
$$

(4) 对 $\hat{x}^{(1)}(k+1)$ 式进行求导还原成预测模型:

$$
\hat{x}^{(0)}(k+1)=-a\left[x^{(0)}(1)-\frac{u}{a}\right] e^{-a t}
$$

(5) 对灰色预测公式进行精确度等级 ${ }^{[15]}$ 检验, 求得后验差比值 $C^{\prime}$ 和小概率频率 $P^{\prime}$, 如果 $P^{\prime}$ 和 $C^{\prime}$ 都在允 许范围之内,则可计算出该项指标的预测值,否则需要通过分析残差序列,对公式进行重新修正。

\section{3 结果分析}

\section{1 生态、经济、社会子系统及综合发展指数分析}

利用熵值法、耦合协调度模型计算得到 2005-2018 年各子系统的发展指数及综合发展指数(图 2)。从 图 2 可以看出,生态子系统发展指数整体呈波动上升趋势,生态基础较好、生态弹性较强; “天保工程”、经济 转型等政策推进,万元 GDP 能耗及万元废水、烟(粉)尘排放量逐年减少,也为生态子系统的发展提供了良好 契机。2006、2011、2014 年生态子系统发展指数有所波动是由于森林覆盖率、农用化肥施用量、建成区绿化覆 盖率波动变化的干扰,这分别反映了生态基础、生态压力、生态响应准则层不稳定对生态子系统发展水平的制 约。总体而言,合理施用农用化肥、提高建成区绿化覆盖率、降低工业能耗及污染,是保持生态基础稳定、提高 生态子系统发展水平的重要保障。

2005-2018 年间,经济子系统发展指数大体呈增长-下滑并停滞-回升发展态势 (图 2)。从图中可以看 出,2005-2013 年经济子系统发展指数呈持续上升态势并在 2013 年达到峰值,经济基础、经济质效准则层发 展指数的持续上升是支持经济子系统发展的主要动力, 拉动其达到峰值的核心因子是固定资产投资率的增 长。2014一-2016 年经济发展回落是由于全面林木禁伐及固定资产投资率的下降,而同期职工平均货币工资 及人均消费品零售额稳步提升,经济质效准则层作用突显并在后期成为拉动经济子系统发展的主要动力。 2017-2018 年经济基础、经济结构准则层发展指数微弱上升,这与伊春固定资产投资率继续回落,产业结构 “退二进一”相呼应。在经济子系统发展过程中应积极发展绿色经济、合理投资固定资产、提高职工工资、提 升人均消费品零售额,在促进经济高质量发展同时避免生态破坏。

社会子系统发展指数总体上呈波动上升的发展态势 (图 2)。2013 年前,社会子系统发展指数持续增长, 增长动力主要来源于社会保障、生活水平准则层; 从因子上看, 养老保险人数、城市居民可支配收人的增加是 促进社会子系统增长的核心因子。2014、2015 年社会子系统发展指数下滑是受到人口就业准则层的影响, 由 于总人口数、自然增长率负向增长,城市人口密度下降导致社会发展活力和动力不足。2016 年后社会子系统 发展指数虽有所回温,但人口就业准则层仍处于较低水平,成为制约社会子系统发展水平的重要因素。因此, 增加居民可支配收人、增强社会保障福利、控制人口收缩、提高人口密度是促进“林竭城衰”城市社会子系统 发展的重要举措。

整体而言,研究期间生态-经济-社会的综合发展指数呈爬坡型增长 (图 2), 是 3 个子系统共同作用的结 果,但各子系统的贡献程度不一。具体而言,2005-2010、2011-2014、2015 年以来 3 个时段对综合发展指数 拉动较大的动力分别为生态子系统、经济子系统、生态子系统, 可见伊春市综合发展的主要动能发生了转换。 从 3 个子系统之间来看,研究期间 3 个子系统的发展水平逐渐趋于协同。但从综合发展指数的实际水平上 
看,尽管 14 年来综合发展指数呈增长态势,但平均值仅为 0.495 ,年均增幅 $7.9 \%$,截止 2018 年综合发展指数 也仅为 0.722 ,综合发展水平仍有很大的提升空间。
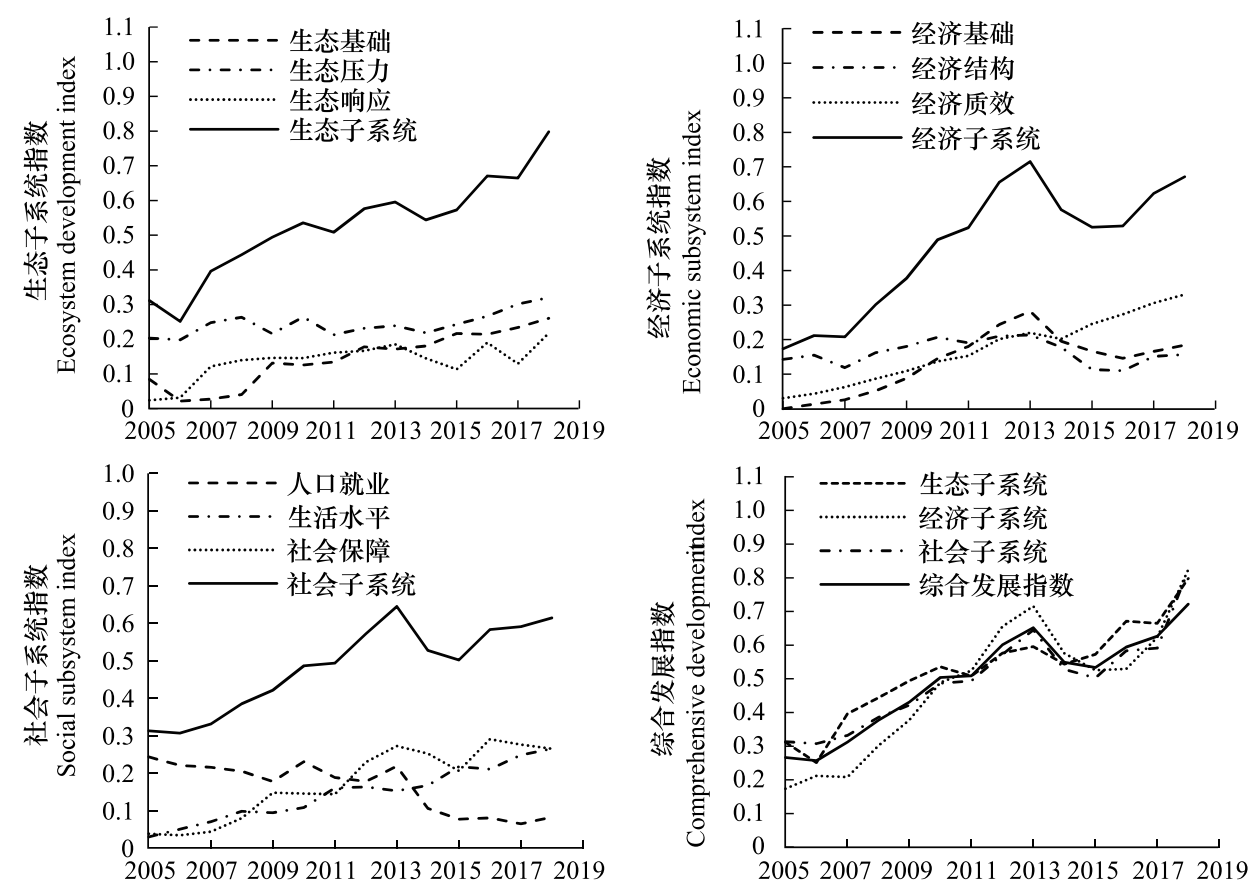

年份 Year

图 2 伊春 2005-2018 年生态子系统、经济子系统、社会子系统发展指数及综合发展指数

Fig.2 Development index of ecological, economic subsystem, social subsystem and comprehensive development index of Yichun from 2005 to 2018

\section{2 耦合协调度分析}

采用耦合协调度模型计算得到伊春生态-经济-社会耦合度及协调度 (表 2)。由表 2 可知, 13 年来伊春生 态-经济-社会的耦合度一直稳定在 0.99 左右,处于高水平耦合阶段, 说明伊春生态、经济、社会子系统发展之 间存在紧密的相互依赖、相互作用关系,但高水平的耦合阶段并不代表高水平的发展阶段,这从生态-经济-社 会综合发展指数上即可证实,如 2005 年耦合度为 0.965 ,但综合发展指数不足 0.3 ,综合发展水平较低。同时, 高水平的耦合也不代表高水平的协调发展,如表 2 所示, 协调度与耦合度的演进过程并不相同,协调度发展呈 波动上升态势,实现了从 2005 年勉强协调状态向 2018 年良好协调状态的转变,大体可分为四个阶段。

（1）2005-2007 年,勉强协调-经济滞后发展。这一时期伊春处于“资源危机、经济危困”的两危境地，“天 保工程” 的实施使得生态环境得到重视, 单一依靠木材资源为基础的经济发展受阻,2005 年起作为资源枯竭 型城市经济转型试点进行转型的效果还未显现, 经济发展滞后于生态、社会子系统发展, 且由于经济发展滞后 及政企合一体制限制,社会发展资金、动力逐渐弱化,社会子系统发展渐缓。

(2)2008-2009 年,初级协调-经济滞后发展。这一时期伊春的经济转型处于探索阶段,经济产值的增长 仍主要来源于第二、第三产业,经济发展虽较前一时期有所改善,但与生态子系统发展指数相比,仍处于滞后 发展, 经济发展不足以支撑社会发展,社会子系统发展愈加趋缓,截止 2009 年, 社会、经济子系统同步滞后 发展。

(3) 2010-2017 年, 中级协调-同步发展。这一时期伊春继续推进“天保工程”及经济转型调整、大力发展 接续产业、积极推进林区“三次创业”, 森林食品北药业“变采为种”, “红蓝黑黄+林药+林畜”产业链引领, 森 林生态旅游不断升级, 木材精深加工持续推进, 绿色矿业逐渐发展, 并实施棚户区改造工程, 生态、经济、社会 子系统发展水平均有所提升并实现同步发展。其中,2013 年的良好协调发展状态是高固定投资拉动下的、虚 
假的高水平协调,并不是经济发展和生态-经济-社会综合发展实际水平和效益的体现。

表 $22005-2018$ 年伊春生态-经济-社会耦合协调度时序变化

Table 2 Degree of coupling and coordination of ecological-economy -society in Yichun from 2005 to 2018

\begin{tabular}{|c|c|c|c|c|}
\hline $\begin{array}{l}\text { 年份 } \\
\text { Year }\end{array}$ & $\begin{array}{l}\text { 耦合度 } \\
\text { Coupling }\end{array}$ & $\begin{array}{c}\text { 协调度 } \\
\text { Coordination degree }\end{array}$ & $\begin{array}{l}\text { 类型 } \\
\text { Sub-types }\end{array}$ & $\begin{array}{l}\text { 状态 } \\
\text { Status }\end{array}$ \\
\hline 2005 & 0.965 & 0.507 & 生态、社会同步发展-经济滞后型 & 勉强协调发展类 \\
\hline 2006 & 0.988 & 0.504 & 生态、社会同步发展-经济滞后型 & 勉强协调发展类 \\
\hline 2007 & 0.966 & 0.549 & 生态发展、社会进步-经济滞后型 & 勉强协调发展类 \\
\hline 2008 & 0.988 & 0.610 & 生态发展、社会进步-经济滞后型 & 初级协调发展类 \\
\hline 2009 & 0.994 & 0.655 & 生态发展-社会、经济滞后型 & 初级协调发展类 \\
\hline 2010 & 0.999 & 0.709 & 生态、经济、社会同步发展型 & 中级协调发展类 \\
\hline 2011 & 1.000 & 0.713 & 生态、经济、社会同步发展型 & 中级协调发展类 \\
\hline 2012 & 0.998 & 0.775 & 生态、经济、社会同步发展型 & 中级协调发展类 \\
\hline 2013 & 0.997 & 0.806 & 生态、经济、社会同步发展型 & 良好协调发展类 \\
\hline 2014 & 0.999 & 0.741 & 生态、经济、社会同步发展型 & 中级协调发展类 \\
\hline 2015 & 0.999 & 0.730 & 生态、经济、社会同步发展型 & 中级协调发展类 \\
\hline 2016 & 0.995 & 0.769 & 生态、经济、社会同步发展型 & 中级协调发展类 \\
\hline 2017 & 0.999 & 0.791 & 生态、经济、社会同步发展型 & 中级协调发展类 \\
\hline 2018 & 1.000 & 0.849 & 生态、经济、社会同步发展型 & 良好协调发展类 \\
\hline
\end{tabular}

（4) 2018 年,良好协调-同步发展。这一时期伊春全面适应停伐政策,积极应对经济下行,着力构建生态 文明建设视角下的生态主体功能区,生态发展稳步提升, 经济运行稳中向好, 社会保障继续推进,生态、经济、 社会子系统基本同步、同向演进,协调度突破 0.8 ,进人良好协调发展状态。未来,更应注重生态、经济、社会子 系统的均衡同步发展, 以生态经济发展为着力点, 提高社会福利保障水平, 以实现林城的内生性优质协调 发展。

\section{3 障碍因子分析}

运用障碍度诊断模型,计算出各子系统的障碍值(图 3)、各年份排名前 5 的障碍因子 (表 3 )。从图 3 可 以看出,3 个子系统对协调发展的障碍度差异较大。2005-2010 年, 3 个子系统障碍值俳徊波动,相对而言, 生态、社会子系统的障碍度较高, 经济子系统的障碍度较小。2011-2018 年,社会子系统障碍值波动上升, 障 碍度最大, 经济子系统障碍度次之, 相对而言, 生态子系统障碍值呈线性下降,截至 2018 年障碍值仅为 0.197 , 与社会、经济子系统障碍度相比很小。由此可见社会子系统始终是制约伊春协调发展的重要因素,实现伊春 近期协调发展的关键在于兼顾生态、经济子系统发展,着重提高社会子系统发展水平。

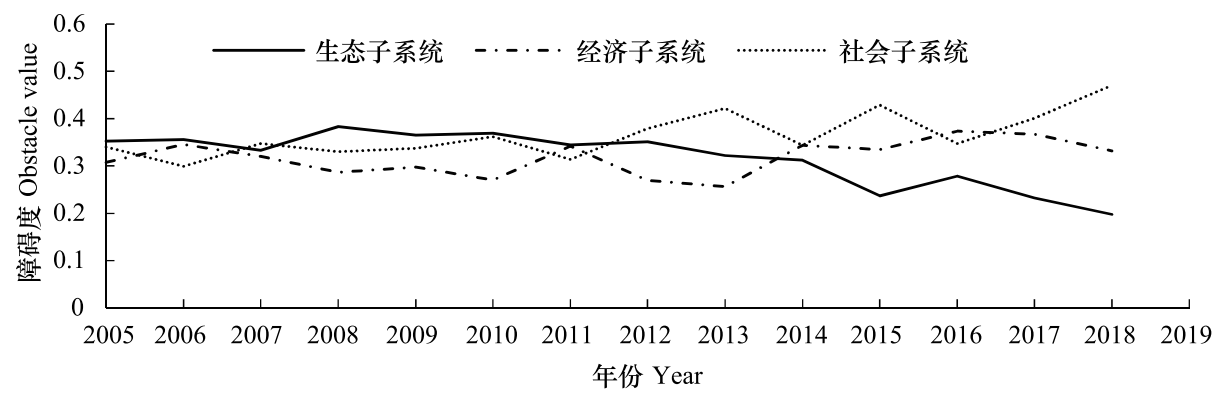

图 3 伊春生态-经济-社会协调发展的系统障碍度变化情况

Fig.3 Changes in the system obstacles on coordination of ecology, economy and society of Yichun from 2005 to 2018

由指标障碍度 (表 3) 可知,影响伊春协调发展的障碍因子并不稳定。依据系统障碍度分析,将研究期间 排名前 5 的障碍因子按 2005-2010、2011-2018 年二阶段划分,并统计其中出现频率 37.5\%以上的指标,将 
其作为二阶段的主要障碍因子 (表 4)。由表 4 可知:2005-2010 年间,污水集中处理率、进出口总额相当于 GDP 占比、社会保障和就业支出占比、恩格尔系数、教育事业费支出相当于 GDP 比重 5 个指标出现频率大于 $50 \%$, 是这一阶段的主要障碍因子; 人口自然增长率、建成区覆盖率、GDP 增长率、第三产业就业人数比重 4 个 指标在 2011-2018 年间出现频率相对较高,将其作为这一阶段制约 3 个子系统协调发展的主要障碍因子。

综上可见,各子系统障碍度及单一指标障碍度是变化的,因此制定生态-经济-社会协调发展的政策也应 审时度势、因时制宜,根据系统障碍度及指标障碍度的转变及时进行政策和对策调整, 以使政策、对策适应发 展变化,措施采取具有针对性。

表 32005 - 2018 年伊春生态-经济-社会协调发展的主要障碍因子障碍度

Table 3 The Obstacle Degrees of the major obstacle factors on coordination of ecology, economy and society of Yichun from 2005 to 2018

\begin{tabular}{|c|c|c|c|c|c|c|c|c|c|c|}
\hline \multirow{3}{*}{$\begin{array}{l}\text { 年份 } \\
\text { Year }\end{array}$} & \multicolumn{10}{|c|}{ 指标排序 Index order } \\
\hline & \multicolumn{2}{|c|}{1} & \multicolumn{2}{|c|}{2} & \multicolumn{2}{|c|}{3} & \multicolumn{2}{|c|}{4} & \multicolumn{2}{|c|}{5} \\
\hline & $\begin{array}{c}\text { 因子 } \\
\text { Obstacle } \\
\text { factor }\end{array}$ & $\begin{array}{c}\text { 障碍度 } \\
\text { Obstacle } \\
\text { degree }\end{array}$ & $\begin{array}{c}\text { 因子 } \\
\text { Obstacle } \\
\text { factor }\end{array}$ & $\begin{array}{c}\text { 障碍度 } \\
\text { Obstacle } \\
\text { degree }\end{array}$ & $\begin{array}{c}\text { 因子 } \\
\text { Obstacle } \\
\text { factor }\end{array}$ & $\begin{array}{c}\text { 障碍度 } \\
\text { Obstacle } \\
\text { degree }\end{array}$ & $\begin{array}{c}\text { 因子 } \\
\text { Obstacle } \\
\text { factor }\end{array}$ & $\begin{array}{c}\text { 障碍度 } \\
\text { Obstacle } \\
\text { degree }\end{array}$ & $\begin{array}{c}\text { 因子 } \\
\text { Obstacle } \\
\text { factor }\end{array}$ & $\begin{array}{c}\text { 障碍度 } \\
\text { Obstacle } \\
\text { degree }\end{array}$ \\
\hline 2005 & $A_{32}$ & 0.1195 & $B_{23}$ & 0.1184 & $A_{12}$ & 0.1176 & $C_{23}$ & 0.1145 & $C_{34}$ & 0.1117 \\
\hline 2006 & $A_{32}$ & 0.0934 & $B_{23}$ & 0.0931 & $C_{23}$ & 0.0911 & $C_{32}$ & 0.0791 & $B_{21}$ & 0.0787 \\
\hline 2008 & $A_{32}$ & 0.0525 & $A_{23}$ & 0.0525 & $C_{34}$ & 0.0525 & $C_{32}$ & 0.0517 & $A_{21}$ & 0.0493 \\
\hline 2009 & $A_{32}$ & 0.0417 & $B_{22}$ & 0.0417 & $A_{24}$ & 0.0417 & $C_{32}$ & 0.0416 & $C_{13}$ & 0.0410 \\
\hline 2010 & $B_{31}$ & 0.0429 & $A_{24}$ & 0.0429 & $A_{31}$ & 0.0429 & $A_{23}$ & 0.0428 & $B_{12}$ & 0.0426 \\
\hline 2011 & $A_{31}$ & 0.0465 & $A_{12}$ & 0.0459 & $A_{13}$ & 0.0459 & $A_{22}$ & 0.0457 & $C_{22}$ & 0.0456 \\
\hline 2012 & $C_{22}$ & 0.0481 & $B_{32}$ & 0.0477 & $A_{31}$ & 0.0474 & $A_{13}$ & 0.0473 & $C_{33}$ & 0.0473 \\
\hline 2013 & $B_{34}$ & 0.0527 & $C_{13}$ & 0.0526 & $C_{12}$ & 0.0526 & $C_{21}$ & 0.0524 & $A_{31}$ & 0.0523 \\
\hline 2014 & $C_{11}$ & 0.0462 & $C_{12}$ & 0.0461 & $B_{13}$ & 0.0461 & $C_{32}$ & 0.0460 & $B_{21}$ & 0.0459 \\
\hline 2015 & $C_{33}$ & 0.0492 & $C_{11}$ & 0.0491 & $B_{21}$ & 0.0471 & $C_{23}$ & 0.0468 & $C_{12}$ & 0.0455 \\
\hline 2016 & $A_{12}$ & 0.0659 & $C_{14}$ & 0.0653 & $C_{12}$ & 0.0651 & $B_{33}$ & 0.0645 & $B_{12}$ & 0.0643 \\
\hline 2017 & $C_{14}$ & 0.0829 & $B_{33}$ & 0.0776 & $B_{12}$ & 0.0704 & $C_{32}$ & 0.0696 & $C_{23}$ & 0.0684 \\
\hline 2018 & $C_{14}$ & 0.1054 & $C_{12}$ & 0.1054 & $B_{33}$ & 0.0964 & $B_{13}$ & 0.0890 & $A_{33}$ & 0.0797 \\
\hline
\end{tabular}

表 42005 -2018 年伊春生态-经济-社会协调发展的主要障碍因子出现频率

Table 4 Occurrence frequency of major obstacles on coordination of ecology, economy and society of Yichun from 2005 to 2018

\begin{tabular}{|c|c|c|c|c|c|c|c|c|c|}
\hline \multirow{2}{*}{$\begin{array}{l}\text { 年份 Year } \\
\text { 障碍因子 Obstacle factor }\end{array}$} & \multicolumn{5}{|c|}{$2005-2010$} & \multicolumn{4}{|c|}{$2011-2018$} \\
\hline & $A_{32}$ & $B_{23}$ & $C_{23}$ & $C_{32}$ & $C_{34}$ & $C_{12}$ & $A_{31}$ & $B_{33}$ & $C_{14}$ \\
\hline 出现频率 Occurrence frequency/\% & 83.3 & 50.0 & 50.0 & 50.0 & 50.0 & 62.5 & 37.5 & 37.5 & 37.5 \\
\hline
\end{tabular}

\section{4 预测结果分析}

以 2006-2018 年伊春生态、经济、社会子系统发展指数及协调度为基础数据,运用灰色预测模型,对各子 系统发展指数及协调度进行预测 (图 4、图 5), 其 $\mathrm{P}$ 值分别为 $0.9286 、 0.8571 、 0.7857 、 0.8571, \mathrm{C}$ 值分别为 $0.4106 、 0.5404 、 0.4572 、 0.4264$, 均通过预测精确度检验,精度等级分别为合格、勉强合格、勉强合格、合格。从 图 4 可知,2019-2030 年,伊春生态、经济、社会的综合发展指数预测值大小排序为经济 $>$ 生态 $>$ 社会, 短期内 生态、经济、社会子系统发展指数差距较小, 三者基本同步发展。但从长远看来,经济子系统将成为伊春生态经济-社会综合发展指数增长及协调发展的主要驱动力。从图 5 可以看出,2019-2030 年,伊春生态-经济-社 会协调度将呈上升趋势, 说明生态-经济-社会系统三者将更加协调, 但仍需警惕未知因素 (如政策变化等) 对 伊春发展过程的影响, 以保证三者协调发展的健康稳定。

\section{4 讨论与结论}

4.1 讨论

本研究在采用传统上常用的三维系统耦合协调度模型的基础上,加人了障碍度模型及灰色预测模型, 对 
探索林业资源型城市生态-经济-社会耦合协调发展的障碍因子及未来发展态势具有一定意义,能够加深对复 合系统协调发展的认识,也使分析更加全面。

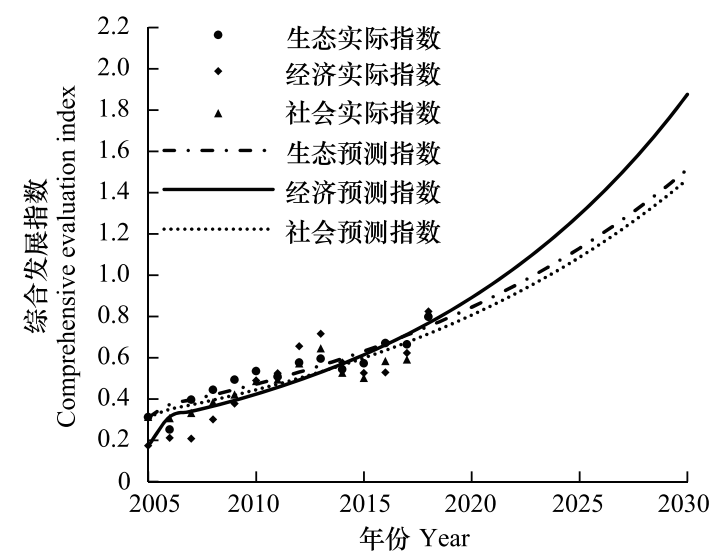

图 4 各子系统发展指数预测曲线

Fig.4 Development index prediction curve of each subsystem

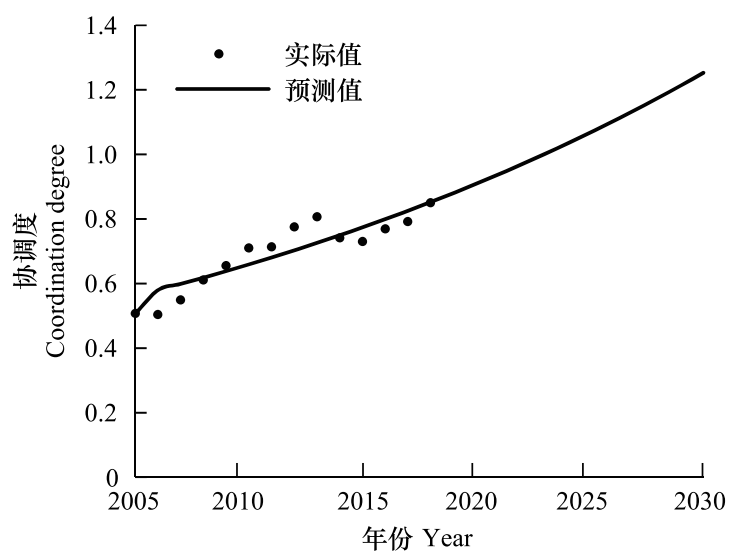

图 5 协调度的预测曲线

Fig.5 Prediction curve of coordination degree

通过对伊春 2005-2018 年生态-经济-社会的耦合协调发展研究发现: 伊春 2005-2018 年生态-经济-社 会三维系统协调发展状态由勉强协调-经济滞后发展向良好协调-同步发展类型转变。这一结果与伊春 2007-2011 年生态-经济二维系统协调发展及 2012-2016 年二维系统协调发展预测的状态研究 ${ }^{[38]}$ 具有一致 性, 本文印证了其研究结论, 并将二维系统扩展到三维,相比之下, 三维系统的研究有助于认识二维系统间的 互动关系。但这一结果与伊春 2006-2014 年生态与经济社会耦合发展研究中历经生态损益型-发展同步型生态主导型的研究结果 ${ }^{[31]}$ 有所不同, 原因是本文中将生态、经济、社会作为 3 个子系统进行研究, 更能显示生 态、经济、社会各个系统的发展差异, 与经济社会合并成一个系统与生态系统进行研究划分协调类型 ${ }^{[31]}$ 相比 较,划分更加具体、细致。

采用障碍度模型进行障碍度诊断发现, 相比较而言, 社会子系统障碍度始终保持在较高水平, 是制约协调 发展的重要因素,其中人口自然增长率是制约伊春近期协调发展的核心指标。这是因为人口负增长下劳动年 龄人口将逐年减少且老龄化程度将逐年增高, 对城市经济发展的人口支撑及社会子系统公共服务发展造成压 力, 从而制约了系统间的协调发展。已有研究证实人口负增长滞后于劳动年龄人口负增长, 先于老年人口负 增长, 且与人口老龄化之间可能存在相互强化 ${ }^{[39]}$, 应控制人口收缩, 稳定人口就业, 提高社会保障度, 并与生 态、经济子系统发展有机结合起来, 以实现生态、经济、社会的多赢发展。

本文在构建指标体系时, 由于指标数据限制, 林区特色性还有体现的空间,加之生态-经济-社会系统间作 用的复杂性和动态性, 如何进一步优化模型方法有待深人探讨。此外, 预测模型的选择是决定未来预测可靠 性的重要基础, 文中运用灰色预测模型进行预测, 预测精度还有很大的提升空间。未来,优化指标体系构建以 更好凸显林区特色, 选择更合适的预测方法提高预测精度, 并在协调发展评价分析基础上,探索林业资源型城 市生态-经济-社会健康协调发展的路径建议是今后的研究方向。

\section{2 结论}

针对林业资源型城市伊春生态-经济-社会协调发展问题, 本文基于各子系统的发展水平, 分析三维系统 耦合协调度、制约协调发展的障碍因子, 并预测了 2019-2030 年各子系统的发展指数及协调度。结果表明: (1)2005-2018 年间,生态-经济-社会 3 个子系统发展不均衡, 促进伊春综合发展指数增长的动能历经了生 态-经济-生态为主趋于协同的转换; (2) 2005-2018 年间,生态-经济-社会的耦合度稳定在较高水平, 协调度 的发展呈现波动上升态势, 实现了从 2005 年勉强协调、经济滞后发展向 2018 年良好协调、同步发展的转变; 
(3) 从系统层中看, 社会子系统是阻碍协调发展的主要系统; 从单一指标层中看, 人口自然增长率、建成区绿 化覆盖率、GDP 增长率、第三产业就业人数比重 4 个指标是 2011-2018 年间制约子系统协调发展的主要障碍 因子。(4)2019-2030 年间,伊春生态、经济、社会子系统发展指数及协调度的预测值均呈上升态势,经济发 展将成为促进生态-经济-社会综合发展的主要动力,生态-经济-社会复合系统将向更高级的协调发展状态 演进。

伊春在重视生态环境的生态效益与经济价值,注重环境治理与保护的同时,政府要推进政策环境优化,加 强生态建设,引导生态创新。深人综合开发森林资源, 大力发展林下经济, 打造北药、绿色食品等特色产业品 牌基础上,培育“生态文旅与康养结合”增长点,构建森林生态产业体系。发挥国家主体生态功能区优势, 探 索“生态银行” 发展模式,推进森林生态资源资产化试点, 逐步发展“碳交易” 经济, 服务国家“碳中和”目标实 现。优化城镇体系结构,大力发展中心城区,集中人口分布, 提高生活配套设施水平和社会服务质量,减少人 口对生态干扰破坏; 积极扩大就业市场稳定城市人口规模; 提高社会保障水平应对老龄化。

\section{参考文献 (References) :}

[ 1 ] 藏淑英, 吴相利, 伊仙美. 发展接续产业避免资源型城市“林竭城衰”一以黑龙江伊春市接续产业发展研究为例. 经济地理, 2006,26 (4) : 589-593.

[ 2 ] Lipton M, Jarrett H. Environmental quality in a growing economy. The Economic Journal, 1968, 78(310) : 440-442.

[ 3 ] Cumberland J H. A regional interindustry model for analysis of development objectives. Papers of the Regional Science Association, 1966, 17(1): 65-94.

[ 4 ] Grossman G M, Krueger A B. Economic growth and the environment. The Quarterly journal of Economics, 1995, 110(2) : 353-377.

[ 5 ] Stern D I, Common M S, Barbier E B. Economic growth and environmental degradation: the environmental Kuznets curve and sustainable development. World Development, 1996, 24(7) : 1151-1160.

[ 6 ] Dinda S. Environmental Kuznets curve hypothesis: a survey. Ecological Economics, 2004, 49(4) : 431-455.

[ 7 ] Martínez M L, Intralawan A, Vázquez G, Pérez-Maqueo O, Sutton P, Landgrave R. The coasts of our world: ecological, economic and social importance. Ecological Economics, 2007, 63(2/3): 254-272.

[ 8 ] Dogan E, Turkekul B. $\mathrm{CO}_{2}$ emissions, real output, energy consumption, trade, urbanization and financial development: testing the EKC hypothesis for the USA. Environmental Science and Pollution Research, 2016, 23(2): 1203-1213.

[ 9 ] Suzuki S, Nijkamp P. An evaluation of energy-environment-economic efficiency for EU, APEC and ASEAN countries: design of a target-oriented DFM model with fixed factors in data envelopment analysis. Energy Policy, 2016, 88: 100-112.

[10] Charfeddine L, Mrabet Z. The impact of economic development and social-political factors on ecological footprint: a panel data analysis for 15 MENA countries. Renewable and Sustainable Energy Reviews, 2017, 76: 138-154.

[11] 王少剑, 方创琳, 王洋. 京津冀地区城市化与生态环境交互耦合关系定量测度. 生态学报, 2015, 35(7): 2244- 2254.

[12］陈晓红, 万鲁河. 城市化与生态环境耦合的脆弱性与协调性作用机制研究. 地理科学, 2013, 33(12): 1450- 1457.

[13] Liu Y B, Yao C S, Wang G X, Bao S M. An integrated sustainable development approach to modeling the eco-environmental effects from urbanization. Ecological Indicators, 2011, 11(6): 1599-1608.

[14] 吴玉鸣, 张燕. 中国区域经济增长与环境的耦合协调发展研究. 资源科学, 2008, 30(1): 25-30.

[15] 周成, 冯学钢, 唐睿. 区域经济-生态环境-旅游产业耦合协调发展分析与预测一一以长江经济带沿线各省市为例. 经济地理, 2016, 36 (3) : 186-193.

［16］刘定惠, 杨永春. 区域经济-旅游-生态环境耦合协调度研究——安徽省为例. 长江流域资源与环境, 2011, 20(7): 892-896.

[17] 马世骏, 王如松. 社会-经济-自然复合生态系统. 生态学报, 1984, 4(1) : 1-9.

[18］毛汉英. 县域经济和社会同人口、资源、环境协调发展研究. 地理学报, 1991, 46(4)：385-395.

[19] 李茜, 胡吴, 李名升, 张殷俊, 宋金平, 张建辉, 张风英. 中国生态文明综合评价及环境、经济与社会协调发展研究. 资源科学, 2015, 37 (7) : 1444-1454.

[20］李秋雨, 朱麟奇, 王吉玉. 全域旅游背景下吉林省旅游业-经济-社会-生态环境协调性研究. 地理科学, 2020, 40(6): 948-955.

[21] 张青峰, 吴发启, 王力, 王健. 黄土高原生态与经济系统耦合协调发展状况. 应用生态学报, 2011, 22(6): 1531-1536.

[22] Fan Y P, Fang C L, Zhang Q. Coupling coordinated development between social economy and ecological environment in Chinese provincial capital cities-assessment and policy implications. Journal of Cleaner Production, 2019, 229: 289-298. 
[23] 马亚亚, 刘国彬, 张超, 王杰. 陕北安塞县生态与经济系统耦合协调发展. 生态学报, 2019, 39(18): 6840-6849.

[24] 倪维秋. 中国三大城市群城市土地利用经济、社会、生态效益的耦合协调性及其空间格局. 城市发展研究, 2016, 23(12)：69-77.

[25] Edenhoffer K, Hayter R. Restructuring on a vertiginous plateau: the evolutionary trajectories of British Columbia's forest industries $1980-2010$. Geoforum, 2013, 44: 139-151.

[26] 藏淑英, 李丹, 韩冬冰. 资源型城市转型与循环经济发展一一黑龙江省伊春市为例. 经济地理, 2006, 26(1): 78-82, $105-105$.

[27] 王玉芳, 杨凤均, 周妹, 刘华根. 大小兴安岭国有林区生态建设水平和经济转型能力评价. 林业经济, 2016, 38(4): 13-19.

[28］吴相利, 庄海燕. 伊春市可持续发展系统仿真模拟与调控研究. 中国人口・资源与环境, 2014, 24(S3) : 399-402.

[29] Markey S, Halseth G, Manson D. The struggle to compete: from comparative to competitive advantage in northern British Columbia. International Planning Studies, 2006, 11(1): 19-39.

[30] Sampson K A, Goodrich C G, Taylor N C. A social assessment of community response to forest policy change in South Westland, New Zealand. Society \& Natural Resources, 2007, 20(3): 199-212.

[31] 张朝辉, 耿玉德. 伊春林业资源型城市的生态与经济社会系统耦合发展研究. 林业经济问题, 2016, 36( 1) : 24-28.

[32］国家环保总局. 关于印发《生态县、生态市、生态省建设指标 (修订稿)》的通知. (2007-12-26) [2020-09-06]. http://www. mee.gov.cn/ $\mathrm{gkml} / \mathrm{zj} / \mathrm{wj} / 200910 / \mathrm{t} 20091022 \_172492 . \mathrm{htm}$.

[33] He Y X, Jiao Z, Yang J. Comprehensive evaluation of global clean energy development index based on the improved entropy method. Ecological Indicators, 2018, 88: 305-321.

[34] 刘浩, 张毅, 郑文升. 城市土地集约利用与区域城市化的时空耦合协调发展评价一以环渤海地区城市为例. 地理研究, 2011, 30(10): $1805-1817$.

[35] 廖重斌. 环境与经济协调发展的定量评判及其分类体系一以珠江三角洲城市群为例. 热带地理, 1999, 19(2): 171-177.

[36] 周涁, 赵宽, 钟林生, 陈田, 虞虎. 舟山群岛生态系统健康与旅游经济协调发展评价. 生态学报, 2015, 35(10): 3437-3446.

[37] 邓聚龙. 灰色系统基本方法(第二版). 武汉: 华中科技大学出版社, 2005.

[38] 曹娟娟, 邢悦, 李臣. 伊春林区生态与经济系统耦合协调度分析. 中南林业科技大学学报: 社会科学版, 2014, 8(1): 95-99.

[39] 张现苓, 翟振武, 陶涛. 中国人口负增长: 现状、未来与特征. 人口研究, 2020, 44(3) : 3-20. 